\title{
Sexual Disinhibition under Sexual Arousal: \\ Evidence for Domain Specificity in Men and Women
}

\author{
Roland Imhoff ${ }^{1,3} \&$ Alexander F. Schmidt ${ }^{2}$
}

Accepted for publication in

Archives of Sexual Behavior

Please do not distribute without the authors' explicit permission.

${ }^{1}$ Sozialpsychologie: Social Cognition, Department of Psychology, University of Cologne, Germany

${ }^{2}$ Social and Legal Psychology, Department of Psychology, University of Bonn, Germany

${ }^{3}$ To whom correspondence should be addressed at Department of Psychology, RichardStrauss-Str. 2, 50931 Cologne, Germany; e-mail: rimhoff@uni-koeln.de

Author note:

We would like to thank Andreas Dierksmeier, Lena Hempel, and Jessica Voller for help in data collection; Lisa Kistemaker and Judith Koppehele-Gossel for translating; and Stefanie Otten for reading the stories in Study 2. This study was realized within the MiKADO Project, funded by the German Federal Ministery of Family Affairs, Senior Citizens, Women and Youth. 


\begin{abstract}
Men have been shown to estimate their likelihood of engaging in sexually coercive behaviors and also uncommon and unprotected sexual behaviors as higher when they are in an acute state of sexual arousal. The present research sought to test (1) whether sexual arousal effects could be replicated under more controlled laboratory settings, (2) whether women showed the same pattern of results, and (3) whether this effect was specific to sexual disinhibition or would generalize to non-sexual disinhibited behavior. In two experimental studies male and female participants (Study 1: $N=84$; Study 2: $N=86$ ) were either sexually aroused by acoustically presented erotic narratives or listened to sexually non-arousing neutral narratives. Afterwards, they self-estimated their likelihood of engaging in a variety of behaviors that could be characterized as sexual or nonsexual disinhibited behavior. Results replicated the previously established effect of sexual disinhibition under sexual arousal for men and provided the first evidence for a similar effect in women. No arousal effects were observed for non-sexual behavior, rendering alternative explanations based on mere indifferent responding unlikely. The discussion focusses on a plausible explanation for this effect.
\end{abstract}

Key Words: sexual arousal; sexual disinhibition; sex differences; disinhibition 


\section{INTRODUCTION}

Most sexually active people can remember at least one incidence of engaging in a sexual activity they later regretted (e.g., Dickson, Paul, Herbison, \& Silva, 1998; Galperin et al., 2012; Oswalt, Cameron, \& Koob, 2005) such as, for example, infidelity, unprotected and/or unsafe intercourse, or an episode in which one has gone "too far" too early. In the heat of the moment we obviously make decisions that are not always in line with our moral ideals and behavioral standards valued in less "hot" states. Empirical findings indicate that increased sexual desire leads to an underestimation of the dangers of sexual risk behavior (Blanton \& Gerrard, 1997; Ditto, Pizarro, Epstein, Jacobson, \& MacDonald, 2005). Also, acute sexual arousal boosts other sexually disinhibited behaviors in men, including a broadened range of sexual interest and a greater willingness to engage in sexually coercive behavior (Ariely \& Loewenstein, 2006). In the present paper we sought to replicate and expand Ariely and Loewenstein's findings by (1) reproducing sexual arousal effects under more controlled laboratory settings, (2) testing whether the effects apply to women, and (3) exploring whether the effects of sexual arousal are specific to sexual disinhibition or would generalize to non-sexual disinhibited behavior.

Surprisingly little scholarly research has experimentally manipulated sexual arousal to test its effect on outcome variables such as disinhibition, evaluation, and decision making. This stands in stark contrast to a large amount of research elucidating either the very phenomenon of sexual arousal and its time course (e.g., Janssen, Everaerd, Spiering, \& Janssen, 2000; O'Donohue \& Geer, 1985; Rosen \& Beck, 1988; Singer, 1984) or physiological and subjective sexual arousal as an outcome, that is, a dependent variable (Adams, Wright, \& Lohr, 1996; Barbaree, Blanchard, \& Langton, 2003; Chivers \& Bailey, 2005; Geer \& Fuhr, 1976). 
Regarding the effects of sexual arousal, many studies have measured subjective or genital sexual arousal and found that individual differences in sexual arousal in response to arousing stimuli were associated with individual differences in the self-reported readiness to engage in unprotected sex (Abbey, Saenz, \& Buck, 2005; Norris et al., 2009) or differences in self-estimated likelihood to sexually aggress in men (Davis, Norris, George, Martell, \& Heiman, 2006a). Measured sexual arousal has also been found to mediate the effects of alcohol on the likelihood of agreeing to unprotected sex in men and women (George et al., 2009; Prause, Staley, \& Finn, 2011), women's rape myth acceptance (Davis, Norris, George, Martell, \& Heiman, 2006b), and men's self-rated likelihood to sexually aggress (Davis et al., 2006a). Although these studies provide important insight in the dynamics of sexual decision making, it is unclear whether acute sexual arousal or individual differences in arousability (or any other third variable) are the causal factors. To further exemplify this limitation, consider the finding that men's sexual arousal in response to a rape scenario predicted their self-rated likelihood to behave like the aggressor (Davis et al., 2006a). While it may very well be that this proneness to become sexually aggressive is directly caused by the arousal, it is equally plausible that some men are less inhibited in their sexual responding by depictions of nonconsensual sex and that these a priori differences determined the stronger arousal as well as the self-reported likelihood to commit sexually aggressive acts.

It is therefore important to add to this literature by experimentally inducing sexual arousal in order to elucidate its causal impact on decision making. Unfortunately, previous studies that have experimentally manipulated sexual arousal of men and women have sometimes failed to find clear main effects of arousal (Macapagal, Janssen, Fridberg, Finn, \& Heiman, 2011; Ruiz-Díaz, Hernández-González, Guevara, Amezcua, \& Ågmo, 2012). Experimentally induced sexual arousal, however, has been shown to increase general approach behavior (Both, Spiering, Everaerd, \& Laan, 2004) and to affect the self-estimated 
likelihood of engaging in various sexual activities (Ariely \& Loewenstein, 2006), a study particularly relevant for the present research. Ariely and Loewenstein instructed men either to masturbate (to sexually explicit imagery presented on screen) or not to masturbate (no images on the screen) while - at the same time - responding to questions from three broad sexually relevant categories: the attractiveness of different sexual activities, the lengths the respondent would go to in order to obtain sexual gratification, and the respondent's attitude toward sexual risks. Parsimoniously, these three domains might be described as examples of sexual disinhibition $^{1}$, defined as (hypothetical) behavior that is more instrumental to gratify personal desires than to conform with perceived social rules (i.e., social desirability). In line with the authors' assumption sexual arousal indeed strengthened the sexual appetitive system: Across all three domains sexually aroused participants estimated their own likelihood to engage in the respective activities as greater than non-aroused participants did. Despite the fact that Ariely and Loewenstein's study clearly constitutes an important pioneering work, it had methodological limitations that we sought to address.

Although it is never explicitly mentioned in the article, it seems that participants in the original study received laptops with the computer experiment to take home before they "returned the laptop to the experimenter on the following day" (Ariely \& Loewenstein, 2006, p. 91). Although this form of data collection might be seen as particularly ecologically valid, it is also at the same time a liability that the experimenters had no control over the situation in which the respondents completed the study. A second methodological problem is that the task

\footnotetext{
${ }^{1}$ It is important to note here that we propose the term disinhibition as a characterization of the commonality of the three domains: Engaging in uncommon, morally questionable, and unsafe sexual behavior. Importantly, disinhibition here refers to the outcome of reporting greater likelihood of engaging in this behavior (i.e., an outcome that is less constrained by social norms and expectations of what might constitute socially desirable responses), not to the process. In terms of underlying processes, such an outcome may results from either reduced inhibitory processes or stronger approach motivation (see Toates, 2009; for a dual control model of inhibition and excitation see also Bancroft \& Janssen, 2000). Although the original authors seemed to favor the latter explanation of an increase in the appetitive sexual system, we argue that alternative explanations are conceivable.
} 
was much more complex in the sexual arousal condition than in the non-aroused condition. Non-aroused participants merely responded to questions by moving a response slider using two keys on a keypad. In contrast, participants in the sexual arousal condition continuously had to navigate between three different screen panels to change sexual stimuli, rate their arousal, and respond to the questions while at the same time continuously masturbating to keep their sexual arousal at a certain predefined level. The fact that the task in the aroused condition - in all likelihood - was more taxing than the task in the non-aroused condition not only decreases comparability between the experimental conditions, but also leaves room for alternative explanations of the results, as we will outline below.

\section{Potential Alternative Explanations}

Ariely and Loewenstein (2006) based their theoretical rationale that sexual arousal strengthens the sexual appetitive system on the more general idea that opportunities for need satisfaction (as implied by delicious food or sexually arousing stimuli) strengthen the motivation to satisfy those respective needs (Rolls, 1999). Although their results are fully in line with this idea, we argue that a similar pattern could be expected based on two alternative explanations of the sexual arousal effect: general disinhibition and/or mere indifferent responding (i.e., giving responses more or less randomly).

A general disinhibition account refers to the possibility that sexual arousal might put participants in a state of reduced inhibition, independent of the inhibition domain (e.g., inhibition of sexual impulses, but also other activities that require either resistance to shortterm temptation, like impulsive eating or smoking, or a mobilization of effort to reach longterm goals, like working out or studying). We have argued above that the items used by Ariely and Loewenstein are likely to yield stronger agreement in a state of disinhibition, that is in "a state in which people do not or only weakly care about what others think of their actions" (van den Bos et al., 2011, p. 794). It is hence conceivable that the observed effects 
were not due to a strengthening of the appetitive system specifically in terms of sexual approach motivations as argued by Ariely and Loewenstein (2006), but to a weakened relevance of social desirability norms. In a state of sexual approach motivation toward active sexual behavior it may indeed be dysfunctional to elaborate too much on how one's actions would be perceived and evaluated by others.

Related to this notion, it could be further argued that answering in accordance with social desirability norms requires self-regulatory resources. The more taxing navigation in the sexual arousal condition in all likelihood also consumed cognitive resources and, thus, might have weakened participants' ability to act in such a self-regulatory manner. Notably, this account receives support from the fact that even in the original study sexual arousal also increased non-sexual risk-taking (see Ariely \& Loewenstein, 2006, footnote 2, p. 90), an outcome commonly seen as an indicator of self-regulatory depletion (Freeman \& Muraven, 2010; Imhoff, Schmidt, \& Gerstenberg, 2013, Study 2).

A second, more critical alternative - not necessarily mutually exclusive - explanation could be based on mere indifferent responding. It is conceivable that individuals did not pay close attention to the questions and clicked their response in a more or less random way. On average, non-aroused participants gave responses that were below the midpoint of the 100point scale (across all items for which an increase under sexual arousal was expected: $M=$ 36.34). In contrast, sexually aroused respondents gave responses around the midpoint on the same items $(M=52.55)$. If non-aroused participants truthfully responded to the questions and (at least some) aroused participants showed more indifferent responding, the same pattern might appear. Sexually aroused participants might have had a decreased motivation to elaborate on the questions due to either sexual disinhibition or the more taxing navigation task and thus might have been less inclined to fine-tune their answers (i.e., clicked more indiscriminately). 


\section{Gender Specificity}

Previous work has primarily focused on men, as does a large portion of sex research, potentially because men have a higher sex drive (Baumeister, Catanese, \& Vohs, 2001) and are also more specific in their sexual responding than (at least heterosexual) women (Chivers, Rieger, Latty, \& Bailey, 2004). Given that there are fundamental differences in sexual behavior and functioning (e.g., Galperin et al., 2012) that has led some authors to propose fundamentally different sexual cognitions for men and women (Ogas \& Gaddam, 2012), we aimed to address these potentially different effects of sexual arousal empirically. Although it may be true that the pathways to the experience of sexual arousal are fundamentally different for men and women (Ogas \& Gaddam, 2012), the consequences might still be the same. Replicating the pattern of sexual disinhibition under sexual arousal not only for men but also in women would constitute an important example of a universal principle of human sexual arousal.

\section{The Present Research}

We thus sought to replicate the findings of Ariely and Loewenstein (2006) in a more controlled laboratory setting, inducing sexual arousal using auditory stimuli that were pretested to be normatively arousing to the majority of participants. As a second alteration, we included men and women to test whether women show a similar effect of sexual arousal on sexual disinhibition. More importantly, we sought to critically address alternative explanations: By including measures of non-sexual disinhibition, we tested the specificity of the sexual arousal effects. If the results reported by Ariely and Loewenstein were due to increased general disinhibition or a weakening of self-regulatory capacities we would expect an effect of sexual arousal on nonsexual disinhibition. Likewise, if sexual arousal merely led to more indiscriminate responding, we would expect an effect on any item that has a mean 
score below the mid-point of the scale for non-aroused participants, such as, for example, items assessing nonsexually disinhibited behavior.

\section{PILOT STUDY}

We translated eight items from Ariely and Loewenstein (2006) to tap into sexual disinhibition and purpose-designed eight items to tap into nonsexual disinhibition. To provide empirical support for our notion that the type of items employed in Ariely and Loewenstein (2006) and our newly generated nonsexual disinhibition control measures are indeed reflective of disinhibition, we conducted a pilot study. Closely aligned with our abovementioned definition of disinhibition, participants in the pilot study were asked to respond to these items as they would normally respond (control condition) and with the instruction to respond as if they did not care or only weakly cared about what others thought of them (disinhibition condition). Higher scores in the disinhibition condition could be interpreted as the degree to which the items tapped into disinhibition.

\section{METHOD}

Participants. We recruited 101 individuals (61 men, 50 women) for a study on hypothetical behavior via the crowdsourcing marketplace Amazon Mechanical Turk. Participants ranged in age from 18 to $61(M=30.3, S D=9.4)$ and received 25 cents for their participation. The majority of participants self-identified as White $(80.2 \%)$ and had a university degree $(52.5 \%)$.

Procedure. All participants first gave demographic information and indicated whether they were primarily sexually oriented toward men or women. They were asked to complete 16 hypothetical questions (the sex of sexual partner in sexual disinhibition items was chosen in accordance with participants' self-identified sexual orientation) with two different instructions that were worded to be consistent with previous experimental manipulations of disinhibition (van den Bos, Müller, \& van Bussel, 2009). One of the instructions read, "We 
are interested in how you would answer the following questions if you were to answer them like you would normally respond when you care about what others think of you" (control condition), whereas the other read "We are interested in how you would answer the following questions if you were to answer them with no inhibitions, that is as if you do not or only weakly care about what others think of you." (disinhibition condition). The 16 questions within each condition were presented in fully randomized order. All participants completed both conditions but the order was counter-balanced across participants. To make sure that participants paid attention to the different instructions, they received a full-page warning between the two item lists ("Attention! On the following page you will be asked to respond to the same questions again but in a different manner. Please read the instruction carefully").

Dependent variables. We translated eight items from the original items employed by Ariely and Loewenstein (2006). Specifically, we selected items on which the sexual arousal manipulation in the original article (masturbation) had produced the largest mean differences (greater than 20 scale points difference between aroused and non-aroused respondents) and that were equally appropriate for men and women (i.e., no explicit date rape items). We purpose-designed analogous items to tap into nonsexual disinhibition, that is, the selfestimated likelihood of engaging in or endorsing behavior that is usually inhibited due to social desirability concerns. All items are presented in Table 1 and were completed on a continuous slider scale ranging from "No" to "Yes". The positions on the scale represented numerical equivalents not visible to participants ranging from 0 ("No) to 100 ("Yes").

Design. The design was a 2 (Order: control condition first vs. disinhibition condition first) by 2 (Participant Gender: male vs. female) by 2 (Condition: control vs. disinhibition) by 2 (Disinhibition Type: sexual vs. nonsexual) mixed-model design with the first two factors being between-subjects factors and the last two factors being within-subjects factors.

\section{RESULTS}


We separately aggregated the eight items representing sexual disinhibition (Cronbach's $\alpha=.63$ in the control condition, $\alpha=.69$ in the disinhibition condition) and nonsexual disinhibition ( $\alpha=.83$ in the control condition, $\alpha=.86$ in the disinhibition condition) for each condition by calculating the mean score for each category. These aggregate scores were then subjected to a 2 (Order) by 2 (Participant Gender) by 2 (Condition) by 2 (Disinhibition Type) mixed-model ANOVA. The notion that higher scores on the selected items could indeed be regarded as indicators of disinhibition was supported by the expected main effect of Condition, $F(1,94)=30.76, p<.001, \eta_{p}{ }^{2}=.25$. If participants were instructed to respond to the items in a disinhibited manner, they produced greater mean scores on the sexual disinhibition scale $(M=40.74, S D=20.29)$ than in the control condition $(M=34.65, S D=$ 17.96), $t(97)=4.93, p<001$, Cohen's $d=0.32$, as well as greater mean scores on the nonsexual disinhibition scale $(M=26.68, S D=20.84)$ than under control conditions $(M=$ 19.51, $S D=15.62), t(97)=4.94, p<001$, Cohen's $d=0.39$. Importantly, both scales were comparably susceptible to the disinhibition instruction, as indicated by a non-significant interaction of Condition and Disinhibition Type, $F<1$. No other interaction with the Condition factor emerged.

\section{DISCUSSION}

The finding that both scales showed higher scores when participants were instructed to respond as if they had no inhibitions indicated that increased scores on these measures can indeed be interpreted as assessments of disinhibition. Crucially, this effect was not stronger for items tapping into sexual disinhibition than for items tapping into nonsexual disinhibition. These two scales are, thus, adequate for putting the specificity of disinhibition under sexual arousal to a fair test.

\section{EXPERIMENT 1}


We tested the effect of experimentally induced sexual arousal on the pilot-tested measures of sexual and nonsexual disinhibition in a sample of male and female students. An effect of sexual arousal on sexual but not nonsexual disinhibition would speak to the specificity of the effects of arousal, whereas an effect on both sexual and nonsexual disinhibition would corroborate non-specific processes of either general disinhibition and/or indifferent responding.

\section{METHOD}

Participants. University students (45 men, 39 women) were recruited on campus for a computer-guided experiment on the effect of acoustic stimuli on cognitive processing. One man self-identified as homosexual (his exclusion did not alter results), and about $56 \%$ were currently in a relationship. Due to a technical error, age was not recorded for a subset of participants. The average age of those for whom age was recorded $(n=29)$ was 23.3 years, $S D=2.2$ (range from 19 to 27). No other demographic variables were recorded but the general local student population can be described as predominantly White German citizens in the respective age range. All participants received $4 €$ (approx. \$3 US) as a compensation for their participation.

Procedure. Participants gave informed consent to participate in a study that might include erotic stimuli as well as questions about their sexual behavior. Men and women were separately randomized to the sexual arousal vs. control group. They were then asked to put on cushioned headphones, close their eyes and imagine as vividly as possible taking part in the situations that were subsequently presented. After each episode a screen with six questions appeared. The first one was always the manipulation check whereas the following five items tapped into sexual and nonsexual disinhibition. As in the pilot study, questions including a sexual partner were presented in a formulation appropriate for participants' self-reported sexual orientation (i.e., all gay and female participants received items referring to male 
partners). To maximize the chances of replicating the effect on sexual disinhibition (and prevent a drop of arousal before the relevant replication measures were screened) the sexual disinhibition items were always presented before the nonsexual disinhibition items. After answering all items, participants pressed a "Next" button and were led to the next episode and the following item block. After completing three episodes the experiment was over.

Sexual Arousal Manipulation. To manipulate their sexual arousal participants were played three episodes (lasting approximately 2 minutes each) of an explicitly erotic story (a commercial pornographic episode told from a female perspective in which a woman seduces a male sexual partner) vs. a clearly non-erotic story (the description of someone's experiences with cats). Translations of the episodes can be found in Appendix 1.

Both stories were told by a female narrator, as informal pretesting showed that women felt less inclined to identify with stories told from a male perspective and men felt more easily disturbed by a male voice than a female voice. This is corroborated by findings of females reporting higher levels of sexual arousal in reaction to audiotapes of female-initiated sexual interactions as compared to audiotapes of male-initiated activity (Heiman, 1977). Also, men's sexual arousal can be predicted from both watching described actions as an observer as well as imagining oneself as a participant, whereas women's sexual arousal depended more critically on imagining oneself as a participant (Janssen, Carpenter, \& Graham, 2003). Thus, a constant female voice was chosen to ensure that participants of both sexes would have comparable chances of getting sexually aroused by the stimuli.

Manipulation Check. The first question was always a manipulation check asking participants to indicate their current level of sexual arousal ("How sexually aroused are you in this moment?") on a continuous slider scale from 0 (not at all) to 100 (very much).

Dependent Variables. After the manipulation check item appeared five more questions that had to be completed on an analogous slider scale ranging from 0 (No) to 100 (Yes). The 
five questions tapped into either sexual disinhibition or nonsexual disinhibition, but items addressing the former always appeared first. We selected seven items tapping into Sexual Disinhibition $^{2}(\alpha=.65)$ and eight items tapping into Nonsexual Disinhibition $(\alpha=.57)$.

Responses to items were averaged to calculate a composite score of sexual disinhibition and nonsexual disinhibition, respectively.

\section{RESULTS}

As a first step we tested whether our sexual arousal manipulation had the desired effect on the manipulation check of self-estimated arousal in both men and women. To this end we subjected the three ratings of sexual arousal to a 2 (Condition: sexual arousal vs. control) x 2 (Participant Gender: male vs. female) x 3 (Episodes) mixed-model ANOVA. Results revealed that overall the manipulation of sexual arousal was successful, as participants in the sexual arousal condition reported greater sexual arousal $(M=31.68, S D=25.13)$ than those in the control condition $(M=4.21, S D=10.28), F(1,75)=39.31, p<.001, \eta_{p}{ }^{2}=.34$, Cohen's $d=$ 1.43 (Figure 1). Men reported greater arousal than women, $F(1,75)=5.92, p=.02, \eta_{p}^{2}=.07$. The only other significant effect was an interaction of Condition $\mathrm{x}$ Episodes, $F(2,74)=4.16$, $p=.02, \eta_{p}{ }^{2}=.10$, which indicated an increasing arousal over time, but only in the sexual arousal condition. The three-way interaction of Condition, Participant Gender, and Episodes did not reach conventional significance, $F(2,74)=2.71, p=.07, \eta_{p}{ }^{2}=.07$.

As we were only interested in the effect of sexual arousal, we used the aggregated selfestimated arousal across all three episodes to exclude participants who were in the sexual arousal condition but showed no arousal $(M<10 ; n=10)$ as well as participants who

\footnotetext{
${ }^{2}$ Specifically, these were the first six items presented in Table 1. Due to a technical error, item 6 was presented twice (but never on the same page). Excluding one of these items resulted in a somewhat lower reliability of the scale $(\alpha=.61)$ but left the other results unaltered. As the setup consisted of three pages with five questions on each page, it was clear that we could not include all 16 items from the pilot study but had to drop one. To make the test of the specificity of sexual disinhibition as conservative as possible, we decided to use one item more in the nonsexual disinhibition scale.
} 
reported sexual arousal although they were in the control condition $(M>10 ; n=6)^{3}$. All subsequent analyses were conducted without these 16 participants ( 8 men, 8 women). Control analyses that included these individuals generally yielded similar results but with somewhat weaker effects.

To test whether the manipulation of sexual arousal also caused sexual disinhibition, nonsexual disinhibition, or both, we conducted a 2 (Condition) x 2 (Participant Gender) x 2 (Disinhibition Type: sexual vs. nonsexual) mixed-model ANOVA. Results showed that the hypothesized interaction of Condition and Disinhibition Type was significant, $F(1,66)=5.92$, $p=.02, \eta_{p}{ }^{2}=.08$. Specifically, a separate 2 (Condition) $\times 2$ (Participant Gender) betweensubjects ANOVA on the sexual disinhibition scale showed that sexually aroused participants reported more sexual disinhibition than non-aroused participants, $F(1,66)=9.16, p=.004$, $\eta_{p}{ }^{2}=.12^{4}$ (Figure 2). A non-significant interaction with gender, $F<1$, indicated that the effect of sexual arousal on sexual disinhibition was equally large and present for men, Cohen's $d=0.94$, and women, Cohen's $d=0.51$. In contrast to this, the level of nonsexual disinhibition was not contingent on participant gender, sexual arousal, or their interaction, all $p s>.18$.

\section{DISCUSSION}

The results of Study 1 replicated the effect of sexual arousal on sexual disinhibition but also expanded them in in several regards. First of all, the effect of greater sexual disinhibition was replicated under more controlled settings in the laboratory. Second, we also expanded previous results that showed sexual arousal effects on men to women. Finally, we obtained

\footnotetext{
${ }^{3}$ The critical cut-off of ten was chosen as the distribution of values in the control condition showed some variation between zero and ten, whereas values above the threshold were identified as extreme values in a boxplot. Conversely, all values of participants in the arousal condition that fell in the inner fence of the control groups were qualified as not sufficiently susceptible to our arousal manipulation.

${ }^{4}$ This was also true when the excluded participants were included in the analysis, $F(1,82)=3.98, p<.05, \eta_{p}{ }^{2}=$ .05 .
} 
preliminary support that the effect is indeed specific to sexual disinhibition and cannot be attributed to either general disinhibition or indifferent responding.

Despite these important results, there are some methodological limitations to this first study. The experimental induction of sexual arousal was not standardized and, despite the successful manipulation check, the two conditions clearly differed in more features than their potential to induce sexual arousal, as they were chosen as non-representative exemplars of clearly erotic vs. non-erotic stories (e.g., they were different in the degree to which they were captivating and emotion inducing). Although we deem it implausible as an alternative explanation, it is theoretically conceivable that the absence of human characters in the nonerotic story prevented identification with the story and thus reduced an - otherwise observable - effect of listening to any narrative. More importantly, the order of dependent variables after arousal induction was always fixed to present the manipulation check first, then the sexual disinhibition items, followed by the nonsexual disinhibition items. This fixed order was chosen to maximize the chances of a replication, as otherwise it could have been argued that measures of nonsexual disinhibition critically attenuated arousal effects and, thus, a failure to replicate would have been attributable to these interfering items. Although we did indeed replicate the effect of greater sexual disinhibition under sexual arousal conditions, this fixed order provided a comparably conservative test for the nonsexual disinhibition account. It is conceivable that time alone makes experimentally induced sexual arousal fade away during the course of the responding blocks. The later position of nonsexual disinhibition items could, thus, be confounded with decreased sexual arousal. Experiment 2 sought to replicate the findings of Experiment 1 while addressing these limitations.

\section{EXPERIMENT 2}

In the second study we addressed potential problems of Experiment 1 in a systematic manner. First, we created more standardized experimental stimuli (based on stories 
previously used as auditory stimuli in phallometric testing) to realize two more comparable experimental arousal conditions. The potential for an order effect was eliminated by presenting items of nonsexual and sexual disinhibition in randomized order after the sexual arousal induction. To confirm that sexual arousal had not fully faded away before participants completed these items, we put the manipulation check of sexual arousal at the end of the experiment.

\section{METHOD}

Participants. University students (41 men, 45 women; $M_{\text {age }}=24.3, S D_{\text {Age }}=5.6$, independent of sex, $t<1$ ) were recruited on campus. One man and one woman self-identified as homosexual (exclusion did not alter results), and about $63 \%$ were currently in a relationship.

Procedure. Participants were given the information that the study dealt with how humans process auditory presented narratives, that the experiment might include sexually explicit language, and that they would be asked about their sexual behaviors. Again, participants of both genders were separately randomized to the sexual arousal vs. control groups. The protocol closely followed that of Experiment 1 with the important differences that there were four episodes in each condition (as these were independent stories, their order was randomized for each participant), that each episode was followed by four questions in randomized order (two tapping into sexual disinhibition, two tapping into nonsexual disinhibition), and that the manipulation check was included after all other questions had been answered.

Sexual Arousal Manipulation. Instead of commercially available material, we used standardized erotic stories from the Quinsey auditory stimuli set for phallometric testing (Quinsey, Chaplin, \& Upfold, 1984). These stimuli were designed for the induction of sexual arousal and had comparable lengths and structures. The consensual sexual stories have been 
shown to produce a significant increase $(>+1.5 S D$ in penile response) in heterosexual men (Quinsey et al., 1984). We translated four neutral and four consensual heterosexual stories into German. As a further refinement (i.e. standardization) compared to Study 1, all stories were read by the same female actress from her perspective. All stories described social interactions involving individuals. Participants listened to either four sexually arousing or four neutral stories in randomized order (see Appendix 2 for the English language wording of the adapted narratives).

Dependent Variables. Nonsexual Disinhibition and Sexual Disinhibition were assessed with eight items each (see Table 1). After each story, two nonsexual and two sexual disinhibition items appeared. As an important alteration to Study 1, the sequence of these items was fully randomized, thus de-confounding order of items and item content.

Manipulation Check. After listening to all four stories, participants completed a oneitem manipulation check ("How sexually aroused are you by the presented stories?") on a scale from 1 (not at all) to 5 (very much) as the last item of the experiment.

\section{RESULTS}

Again, the sexual arousal condition had an effect on the manipulation check of selfestimated arousal, as participants in the sexual arousal condition described themselves as more aroused, $M=2.72, S D=1.03$, than participants in the neutral condition, $M=1.35, S D=$

$0.57, F(1,83)=59.50, p<.001, \eta_{p}{ }^{2}=.42$ (Figure 3$)$. There was no main effect of Participant Gender, $F(1,83)=1.40, p=.24, \eta_{p}{ }^{2}=.02$, nor was there an interaction of Participant Gender and Condition, $F(1,83)=1.83, p=.18, \eta_{p}{ }^{2}=.02$, suggesting that the manipulation was equally successful for male and female participants. As in Experiment 1, we excluded participants who were in the sexual arousal condition but showed no arousal $(M<2 ; n=6)$, as well as participants who reported sexual arousal although they were in the control 
condition $(M>1 ; n=13)^{5}$. All consecutive analyses were conducted without these 19 participants ( 8 men, 11 women). Keeping them in the sample made the effects weaker but did not change the direction of results.

Conducting the same ANOVA as in Experiment 1 (Condition $\mathrm{x}$ Participant Gender $\mathrm{x}$ Disinhibition Type) revealed that the hypothesized interaction of Condition and Disinhibition Type was again significant, $F(1,63)=4.24, p=.04, \eta_{p}{ }^{2}=.06$. Similar to Experiment 1 , separate ANOVAs indicated that sexual arousal increased sexual disinhibition, $F(1,63)=$ $5.55, p=.02, \eta_{p}{ }^{2}=.08^{6}$, but not nonsexual disinhibition, $F<1$. Men showed higher scores on sexual, $F(1,63)=11.28, p=.001, \eta_{p}{ }^{2}=.15$, and nonsexual disinhibition, $F(1,63)=4.30, p=$ $.04, \eta_{p}{ }^{2}=.06$, but neither of these Participant Gender effects were moderated by Condition, $F_{\mathrm{s}}<1$. Thus, sexual arousal led to sexual but not to nonsexual disinhibition in both men, Cohen's $d=0.48$, and women, Cohen's $d=0.67$.

\section{DISCUSSION}

Experiment 2 replicated the findings of Experiment 1 in a more controlled fashion by using standardized arousal induction stories and fully randomized item orders. Nevertheless, the results remained virtually unaltered. In line with Experiment 1, men showed higher levels of nonsexual disinhibition than women but this was unaffected by sexual arousal. It thus seems that sexual arousal indeed specifically reduces sexual inhibition and not just any conformity to social norms and rules (or leads to merely indifferent responding).

\section{General Discussion}

\footnotetext{
${ }^{5}$ The 5-point scale did not lend itself to a fine-grained analysis of response distributions as in Study 1. Instead, we normatively decided that the control condition should include participants who were clearly non-aroused (lowest response option on the scale), whereas participants in the sexual arousal condition should be at least somewhat aroused (at least a 2 on a 5-point-scale).

${ }^{6}$ When the excluded participants were included in the analyses, the observed effect was in the same direction, but not significant anymore, $F(1,82)=2.59, p=.11, \eta_{p}{ }^{2}=.03$.
} 
The two studies provided concordant support that sexual arousal evokes sexual disinhibition as operationalized by an increased self-reported likelihood to engage in uncommon, risky, and coercive sexual activities. This effect was independent of respondent gender and specific to sexual (but not nonsexual) disinhibition. Hence, situational sexual arousal may function as a previously largely ignored risk factor for (self-reported interest in) socially inadequate, unhealthy, and manipulative sexual behavior.

As an important addition to previous work we established this effect under much more controlled laboratory settings and, more importantly, for women as well as for men. Previous research has largely neglected the issue of whether sexual arousal has an identical effect on women's sexual behavior as it has on men's, presumably because many social problems associated with sexual disinhibition, such as, for example, coercive sexual behavior, are far more frequently observed in men than in women. Nevertheless, the present studies obtained an effect of sexual arousal not only on the arguably predominantly male forms of problematic sexual behavior but also on indicators of sexual risk behavior regarding the protection against sexually transmitted diseases and unwanted pregnancy (both among the top five sexual regrets reported by women; Galperin et al., 2012). As these are real-world problems for women and men (at least sexually transmitted diseases), the negligence of women in research addressing this sexual risk behavior is ill-advised.

The consequences of sexual arousal in women are relevant for real-world problems as argued above, however, they also invite speculation about gender differences in sexual responding. It has often been argued that the different required minimal investment to reproduce between men and women has led to the evolution of fundamentally different sexual systems guiding sexual desire and behavior (Buss, 2003; Townsend, Kline, \& Wasserman, 1995; Symons, 1979). From this perspective, it could be speculated that sexually disinhibited behavior has markedly greater costs for women and it would thus be adaptive for 
women if sexual arousal did not lead to disinhibition, but rather to greater caution, selectivity, and processing of contextual information (Baumeister, 2000; Rupp et al., 2009). Our studies, in contrast, show a remarkable uniformity of the effect of sexual arousal on men's and women's (self-reported) sexual behavior. It may thus be that the described gender differences are predominantly situated in the pathway to sexual arousal, whereas the consequences of (or pathway from) sexual arousal are much more similar for men and women.

Two studies have provided consistent support for the notion that sexual arousal leads to sexual disinhibition (as we label it) but not to nonsexual disinhibition. As an important caveat, our results are tightly connected to the way we have construed disinhibition. We have relied on a phenomenological definition based on a well-established definition in social psychology: Disinhibition is reflected in reduced consideration of what others might think of the respective behavior. This has to be differentiated from definitions that understand (dis)inhibition as an internal mental process. Although it is conceivable that sexual arousal also impaired such internal processes of inhibiting sexual impulses, it cannot be determined from our data whether this is the case or whether sexual arousal merely increases the strength of the sexual impulse (while the inhibition remains unaltered). Future research dedicated to the questions of whether sexual arousal boosts sexual excitation and approach behavior or whether it dampens sexual inhibition and avoidance behavior seems warranted.

Given the available evidence, what seems to be the most plausible model of causal factors creating the observed disinhibitory effects? Our studies ruled out the alternative explanation that sexual arousal merely reduces cognitive capacity to act and respond in a socially desirable manner. Thus, if the effect was due to reduced inhibition, we would need to presume a highly specific system for sexual inhibition which would contradict the idea that goal-directed inhibition is a domain-general process as evidenced in the fact that overly risky behavior seems to generalize across various activities, including unsafe sex (Zuckerman \& 
Kuhlman, 2000). This leaves the idea that sexual arousal strengthens the appetitive sexual system - rendering sexual temptations more salient, appealing, or rewarding - as the most plausible process assumption. A similar argument has been brought forward by Ariely and Loewenstein (2006), who proposed that evolved appetitive systems (i.e., hunger, thirst, mating-relevant behavior) in the brain are designed to increase motivation once they get primed with suitable opportunities (also labelled motivational myopia; Ditto et al., 2006). This would corroborate that motivational salience effects as a consequence of increased sexual arousal drive the domain-specific disinhibition observed in the present studies.

Another open issue is the specificity of the effect of sexual arousal. Although the current data do not speak to any effect on non-sexual forms of disinhibition, Ariely and Loewenstein (2006) did report that sexual arousal also led to more risky decisions (footnote 2, p. 90). How are these results reconcilable? It is conceivable that sexual arousal also triggers approach motivation to tempting stimuli other than sexual stimuli (Gold, 1993). A second possibility is that the limited comparability of the arousing and non-arousing conditions in the Ariely and Loewenstein paper led to other effects that are not due to sexual arousal. We have argued above that the more taxing nature of the arousing condition might also have led to greater ego depletion and resultantly riskier choices (Imhoff et al., 2013) - an effect that was controlled for in this research.

\section{Limitations and future directions}

A clear limitation of the present studies is the reliance on self-reported likelihood of showing sexually risky, manipulative, or uncommon behavior. Whether this reduced weight of how one's actions will be evaluated by others will translate to actual corresponding behavior is of course dependent on many factors other than just the level of sexual arousal (which is true for virtually every behavioral phenomenon). To elucidate the causal contribution of sexual arousal we deemed it necessary to manipulate arousal under controlled 
laboratory settings, which unfortunately are an obstacle to the observation of spontaneous and actual real-life behavior.

Independent of a more fine-grained understanding of the underlying processes involved in the disinhibitory effects of sexual arousal on decision making and behavior, these effects might also provide an explanatory base for other examples of problematic sexual behavior. Neglecting social desirability concerns for the sake of sexual gratification could also be brought forward as an explanation of sexual undesirable behavior like lowered age thresholds for acceptable sexual partners: In a preliminary study, we have found that experimentally induced sexual arousal led to lowered age thresholds for sexual partners accepted as adequate (Imhoff, 2012). This corroborates the importance of situational factors (above and beyond well-documented trait influences) such as sexual arousal in gaining a more complete understanding of sexually undesirable behaviors. Actively searching for sexually pleasing content in a state of acute sexual arousal might increase the risk to access sexually more extreme material because social desirability concerns will be less attended to. In combination with sexual desensitization or satiation, this might lower the threshold for a progression toward increasingly extreme non-deviant and deviant pornography (SeigfriedSpellar \& Rogers, 2013). Maybe even more relevant, in a study on online sexual solicitation, adult men who self-reported having engaged in sexual conversations with children and adolescents reported to have experienced sexual arousal not only during but also before the communication (Bergen et al., 2013). This possible etiological pathway remains speculative at present but, nevertheless, constitutes an important research agenda to gain a better understanding of situational factors in sexual offending.

In conclusion, the present two studies constitute a controlled replication and expansion of the domain-specific disinhibitory effects of sexual arousal. We were able to rule out the potential alternative explanation that sexual arousal merely leads to unspecific social 
undesirable or even merely more indifferent responding. Perhaps most importantly, we showed that these effects are not limited to male sexual arousal but that women show the same pattern of sexual disinhibition under sexual arousal. 


\section{REFERENCES}

Abbey, A., Saenz, C., \& Buck, P. O. (2005). The cumulative effects of acute alcohol consumption, individual differences and situational perceptions on sexual decision making. Journal of Studies on Alcohol, 66, 82-90.

Adams, H. E., Wright, L. W., \& Lohr, B. A. (1996). Is homophobia associated with homosexual arousal? Journal of Abnormal Psychology, 105, 440-445. doi:10.1037/0021-843X.105.3.440

Ariely, D., \& Loewenstein, G. (2006). The heat of the moment: The effect of sexual arousal on sexual decision making. Journal of Behavioral Decision Making, 19, 87-98. doi:10.1002/bdm.501

Bancroft, J., \& Janssen, E. (2000). The dual control model of male sexual response: A theoretical approach to centrally mediated erectile dysfunction. Neuroscience and Biobehavioral Review, 24, 571-579. doi: 10.1016/S0149-7634(00)00024-5

Barbaree, H. E., Blanchard, R., \& Langton, C. M. (2003). The effects of age on sexual arousal and recidivism. In R. A. Prentky, E. S. Janus, \& M. C. Seto (Eds.), Sexually coercive behavior: Understanding and management (pp. 59-71), Annals of the New York Academy of Science, 989.

Baumeister, R. F. (2000). Gender differences in erotic plasticity: The female sex drive as socially flexible and responsive. Psychological Bulletin, 126, 347-374. doi: $10.1037 / 0033-2909.126 .3 .347$

Baumeister, R. F., Catanese, K. R., \& Vohs, K. D. (2001). Is There a Gender Difference in Strength of Sex Drive? Theoretical Views, Conceptual Distinctions, and a Review of Relevant Evidence. Personality and Social Psychology Review, 5, 242-273. doi: 10.1207/S15327957PSPR0503_5 
Bergen, E., Ahto, A., Schulz, A., Imhoff, R., Antfolk, J., Schuhmann, P., ... Jern, P. (2013). Adult- adult and adult- child/adolescent online sexual interactions: An exploratory selfreport study on the role of situational factors. Manuscript submitted for publication.

Blanton, H., \& Gerrard, M. (1997). The effect of sexual motivation on the perceived riskiness of a sexual encounter: There must be fifty ways to justify a lover. Health Psychology, 16, 374-379. doi:10.1037/0278-6133.16.4.374

Both, S., Spiering, M., Everaerd, W., \& Laan, E. (2004). Sexual behavior and sexual responsiveness following laboratory-induced sexual arousal. The Journal of Sex Research, 41, 242-258.

Buss, D. M. (2003). Evolution of desire: The strategies of human mating. New York: Basic Books.

Chivers, M. L., \& Bailey, J. M. (2005). A sex difference in features that elicit genital response. Biological Psychology, 70, 115-120. doi:10.1016/j.biopsycho.2004.12.002

Chivers, M. L., Rieger, G., Latty, E., \& Bailey, J. M. (2004). A sex difference in the specificity of sexual arousal. Psychological Science, 15, 736-744. doi: 10.1111/j.09567976.2004.00750.x

Davis, K. C., Norris, J., George, W. H., Martell, J., \& Heiman, R. J. (2006a). Men's likelihood of sexual aggression: The influence of alcohol, sexual arousal, and violent pornography. Aggressive Behavior, 32, 581-589. 10.1002/ab.20157

Davis, K. C., Norris, J., George, W. H., Martell, J., \& Heiman, R. J. (2006b). Rape myth congruent beliefs in women resulting from exposure to violent pornography: Effects of alcohol and sexual arousal. Journal of Interpersonal Violence, 21, 1208-1223. doi: $10.1177 / 0886260506290428$ 
Dickson, N., Paul, C., Herbison, P., \& Silva, P. (1998). First sexual intercourse: age, coercion, and later regrets reported by a birth cohort. British Medical Journal, 316, 2933. doi: $10.1136 / \mathrm{bmj} .316 .7124 .29$

Ditto, P. H., Pizarro, D. A., Epstein, E. B., Jacobson, J. A., \& MacDonald, T. K. (2006).Visceral influences on risk-taking behavior. Journal of Behavioral Decision Making, 19, 99-113. doi:10.1002/bdm.520

Freeman, N., \& Muraven, M. (2010). Self-control depletion leads to increased risk taking. Social Psychological and Personality Science, 1, 175-181. doi:10.1177/1948550609360421

Galperin, A., Haselton, M. G., Fredrick, D. A., Poore, J., von Hippel, W., Buss, D. M., \& Gonzaga, G. C. (2012). Sexual regret: Evidence for evolved sex differences. Archives of Sexual Behavior. Advance online publication. doi: 10.1007/s10508-012-0019-3

Geer, J. H., \& Fuhr, R. (1976). Cognitive factors in sexual arousal: The role of distraction. Journal of Consulting and Clinical Psychology, 44, 238-243. doi:10.1037/0022$006 X .44 .2 .238$

George, W. H., Davis, K. C., Norris, J., Heiman, J. R., Stoner, S. A., Schacht, R. L., Hendershot, C. S., \& Kajumulo, K. F. (2009). Indirect effects of acute alcohol intoxication on sexual risk-taking: The roles of subjective and physiological sexual arousal. Archives of Sexual Behavior, 38, 498-513. doi:10.1007/s10508-008-9346-9

Gold, R. S. (1993). On the need to mind the gap: On-line versus off-line cognitions underlying sexual risk-taking. In D. J. Terry, C. Gallois, \& M. McCamish (Eds.), The theory of reasoned action: Its application to AIDS-preventive behaviour (pp. 227-252). Oxford: Pergamon Press. 
Heiman, J. R. (1977). A psychophysiological exploration of sexual arousal patterns in females and males. Psychophysiology, 14, 266-274. doi:10.1111/j.14698986.1977.tb01173.x

Imhoff, R. (2012). Sexual arousal decreases minimum age required for sexual partners. Paper presented at Mikado Project Meeting in Turku, Finland.

Imhoff, R., Schmidt, A. F., \& Gerstenberg, F. X. R. (2013). Exploring the interplay of trait self-control and ego depletion: Empirical evidence for ironic effects. European Journal of Personality. Advance online publication. doi:10.1002/per.1899

Janssen, E., Carpenter, D., \& Graham, C. (2003). Selecting films for sex research: Gender differences in erotic film preference. Archives of Sexual Behavior, 32, 243-251. doi:10.1023/A:1023413617648

Janssen, E., Everaerd, W., Spiering, M., \& Janssen, J. (2000). Automatic cognitive processes and the appraisal of sexual stimuli: Towards an information processing model of sexual arousal. Journal of Sex Research, 37, 8-23. doi: 10.1080/00224490009552016

Macapagal, K. R., Janssen, E., Fridberg, D. J., Finn, P. R., \& Heiman, J. R. (2011). The effects of impulsivity, sexual arousability, and abstract intellectual ability on men's and women's go/no-go task performance. Archives of Sexual Behavior, 40, 995-1006. doi: $10.1007 / \mathrm{s} 10508-010-9676-2$

Norris, J., Stoner, S. A., Hessler, D. M., Zawacki, T., Davis, K. C., George, W. H., Morrison, D. M., \& Abdallah, D. A. (2009). Influences of sexual sensation seeking alcohol consumption and sexual arousal on women's behavioral intentions related to having unprotected sex. Psychology of Addictive Behaviors, 23, 14-22. doi:10.1037/a0013998

O'Donohue, W. T., \& Geer, J. E. (1985). The habituation of sexual arousal. Archives of Sexual Behavior, 14, 233-246. doi:10.1007/BF01542106 
Ogas,O., \& Gaddam, S. (2012). A billion wicked thoughts. What the internet tells us about sexual relationships. London: Penguin.

Oswalt, S. B., Cameron, K. A., \& Koob, J. J. (2005). Sexual regret in college students. Archives of Sexual Behavior, 34, 663-669. doi:10.1007/s10508-005-7920-y

Prause, N., Staley, C. \& Finn, P. (2011). The role of acute ethanol consumption in sexual arousal and sexual risk taking, Archives of Sexual Behavior, 40, 373-384. doi: $10.1007 / \mathrm{s} 10508-010-9718-9$

Quinsey, V. L., Chaplin, T. C., \& Upfold, D. (1984). Sexual arousal to nonsexual violence and sadomasochistic themes among rapists and non-sex-offenders. Journal of Consulting and Clinical Psychology, 52, 651-657. doi: 10.1037/0022-006X.52.4.651

Rolls, E. T. (1999). The brain and emotion (pp. 218-243). Oxford: Oxford University Press.

Rosen, R. C., \& Beck, J. G. (1988). Patterns of sexual arousal: Psychophysiological processes and clinical applications. New York: Guilford Press.

Ruiz-Díaz, M., Hernández-González. M., Guevara. M. A., Amezcua, C., \& Ågmo, A. (2012). Prefrontal EEG correlation during Tower of Hanoi and WCST performance: effect of emotional visual stimuli. Journal of Sexual Medicine, 9, 2631-2640. doi: 10.1111/j.1743-6109.2012.02782.x.

Rupp, H. A., James, T. W., Ketterson, E. D., Sengelaub, D. R., Janssen, E., \& Heiman, J. R. (2009). The role of the anterior cingulate cortex in women's sexual decision making. Neuroscience Letters, 449, 42-47. doi: 10.1016/j.neulet.2008.10.083

Symons, D. (1979). The evolution of human sexuality. New York, NY: Oxford University Press.

Seigfried-Spellar, K. C., \& Rogers, M. K. (2013). Does deviant pornography use follow a Guttman-like progression? Computers in Human Behavior, 29, 1997-2003. doi: 10.1016/j.chb.2013.04.018 
Singer, B. (1984). Conceptualizing sexual arousal and attraction. Journal of Sex Research, 20, 230-240. doi:10.1080/00224498409551222

Toates, F. (2009). An integrative theoretical framework for understanding sexual motivation, arousal, and behavior. Journal of Sex Research, 46, 168-193. doi: $10.1080 / 00224490902747768$

Townsend, J. M., Kline, J., \& Wasserman, T. H. (1995). Low-investment copulation: Sex differences in motivations and emotional reactions. Ethology and Sociobiology, 11, $375-424$.

van den Bos, K., Van Lange, P. A., Allan Lind, E., Venhoeven, L. A., Beudeker, D. A., Cramwinckel, F. M., ... \& van der Laan, J. (2011). On the benign qualities of behavioral disinhibition: Because of the prosocial nature of people, behavioral disinhibition can weaken pleasure with getting more than you deserve. Journal of Personality and Social Psychology, 101, 791-811. doi: 10.1037/a0023556

van den Bos, K., Müller, P. A., \& van Bussel, A. A. (2009). Helping to overcome intervention inertia in bystander's dilemmas: Behavioral disinhibition can improve the greater good. Journal of Experimental Social Psychology, 45, 873-878. doi: 10.1016/j.jesp.2009.03.014

Zuckerman, M., \& Kuhlman, D. M. (2000). Personality and risk-taking: Common biosocial factors. Journal of Personality, 68, 999-1029. doi: 10.1111/1467-6494.00124 


\section{Table 1}

Items to Measure Sexual and Nonsexual Disinhibition

Sexual Disinhibition

1. Could you enjoy having sex with someone you hated?

2. If you were attracted to a woman/man and she/he proposed a threesome with a man/woman, would you do it?

3. Would it be fun to tie up your sexual partner?

4. Would you find it exciting to have anal sex?

5. Is just kissing frustrating?

6. Would you use a condom even if you were afraid that a woman/man might change her/his mind while you went to get it? (reverse coded)

7. Would you tell a woman/man that you loved her to increase the chance that she/he would have sex with you?

8. Can you imagine having sex with a 50-year-old woman/man?

Nonsexual Disinhibition

1. Would you enjoy spreading inaccurate rumors?

2. Would you borrow items from friends to keep them for yourself?

3. Does it bore you to listen to friends' problems?

4. Would you be more likely to help friends if you expected them to return the favor?

5. Can you imagine exploiting or shortchanging a friend?

6. If there were a person in need of the seat you occupy on public transportation, would you intentionally ignore the person's need?

7. If you saw someone being attacked on the street, would you intentionally look the other way?

8. Could it happen that you throw litter on the street or in nature even if there were a trash can nearby? 
Figure 1

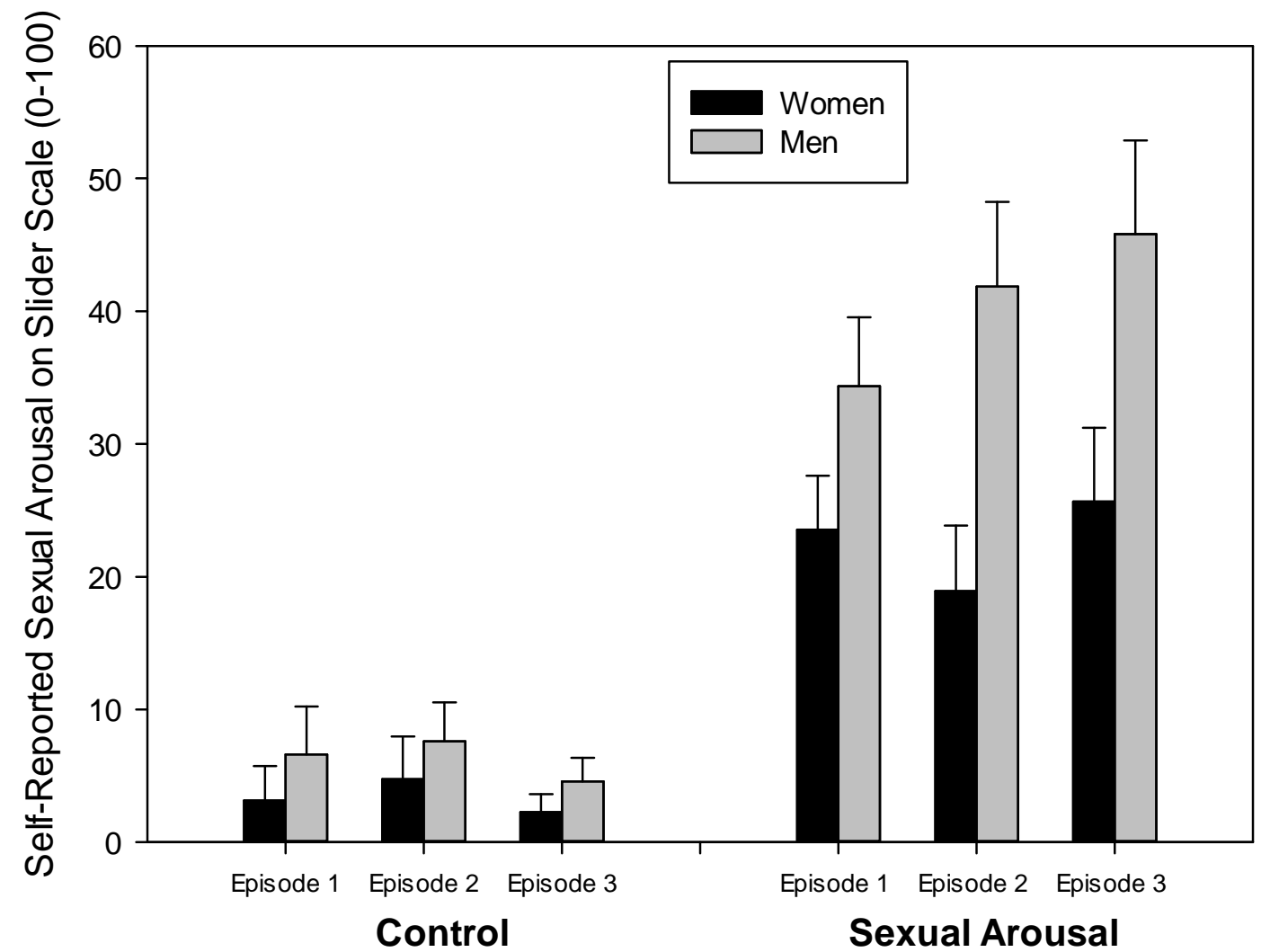

Figure 1. Mean scores (+SE) on manipulation check of self-reported sexual arousal as a function of experimentally induced sexual arousal, episode, and participant gender in Study 1. 
Figure 2

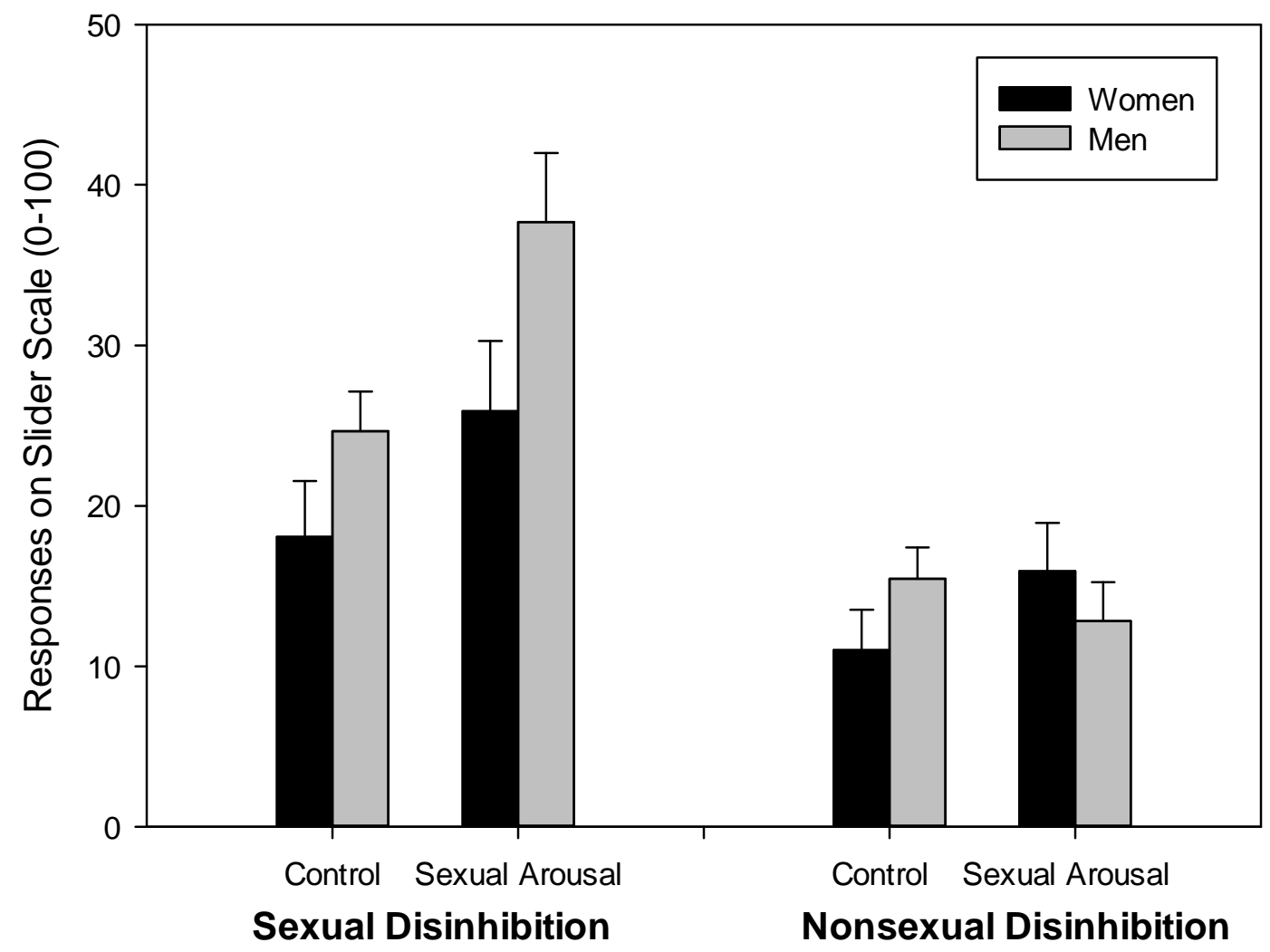

Figure 2. Mean scores $(+\mathrm{SE})$ on measures of sexual and nonsexual disinhibition as a function of experimentally induced sexual arousal and participant gender in Study 1. 
Figure 3

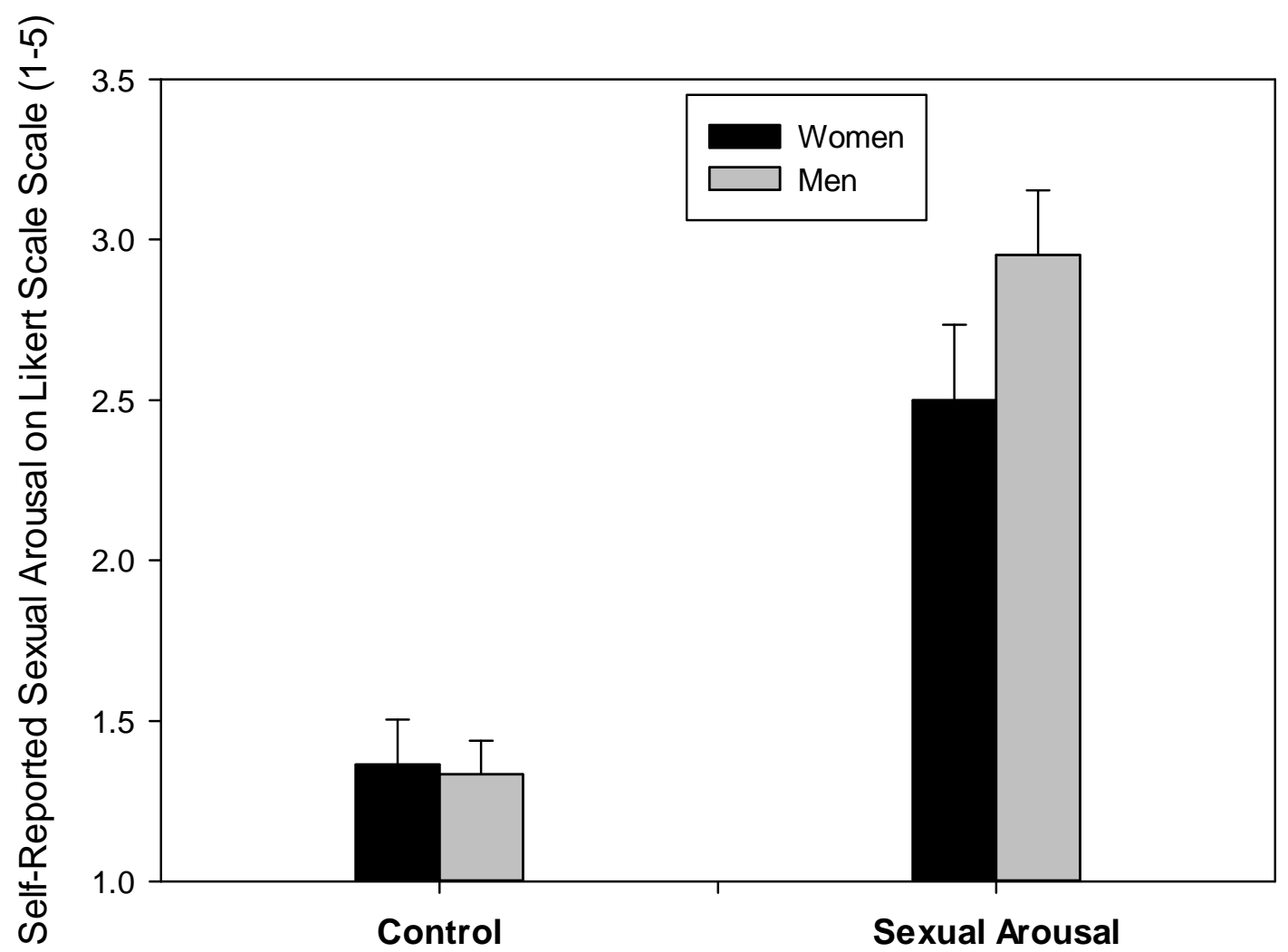

Figure 3. Mean scores (+SE) on manipulation check of self-reported sexual arousal as a function of experimentally induced sexual arousal and participant gender in Study 2. 
Figure 4

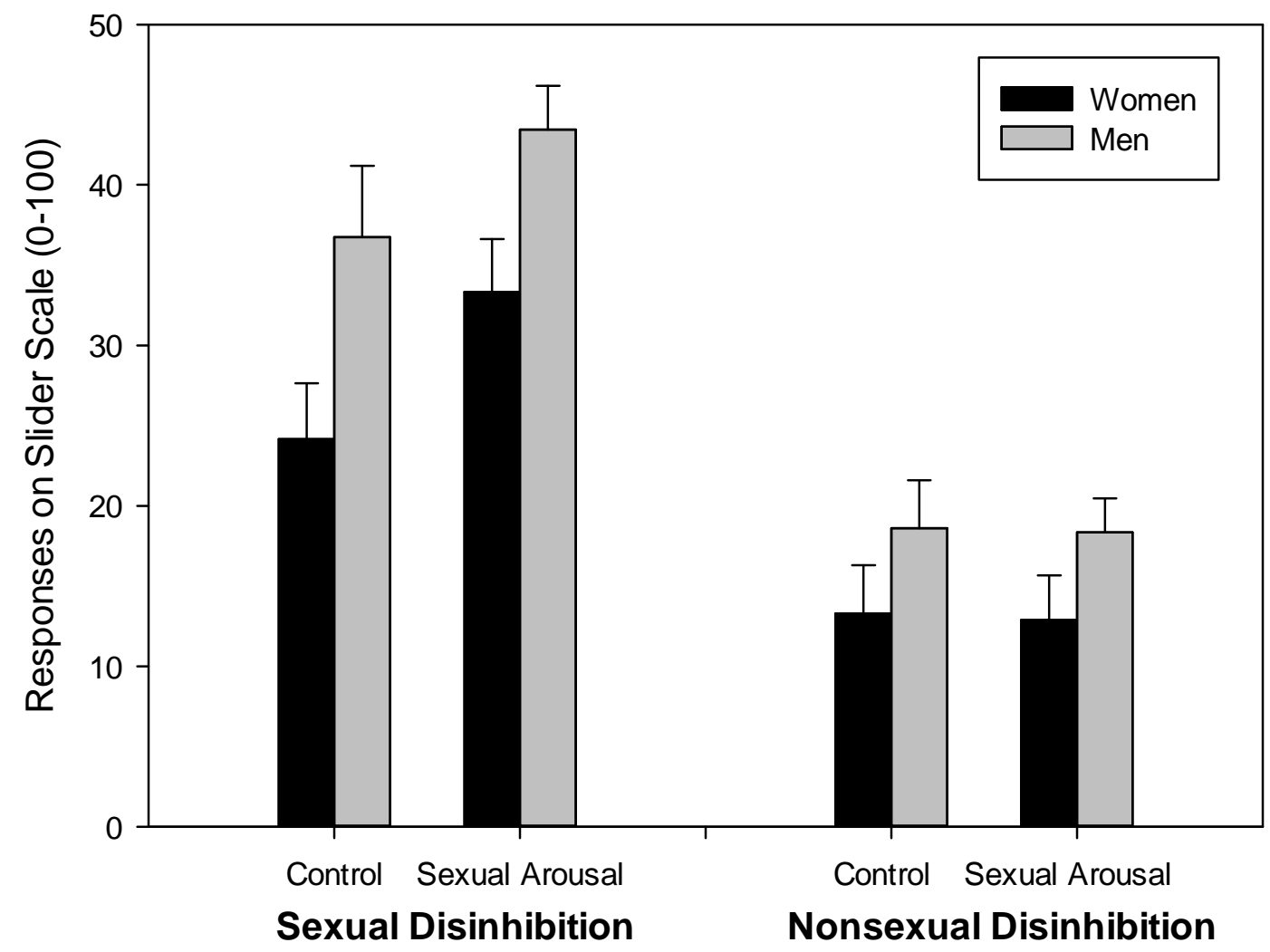

Figure 4. Mean scores (+SE) on measures of sexual and nonsexual disinhibition as a function of experimentally induced sexual arousal and participant gender in Study 2. 


\section{APPENDIX}

\section{Study 1: Erotic Story (Sexual arousal condition)}

\section{Episode 1}

When the football match starts on television, we adjourn to the dining room. Tommy joins us as well. "It's too smoky in the living room," he says and takes a seat at the table next to me. In my head, he causes a flood of images: I see me and him, closely embraced. His naked, young body firmly pressed against mine. When his thigh accidentally touches mine, the animal between my legs wakes up and I start sweating. While he is making friendly conversation, I take a curious glance at his lap. The fabric of his brightly colored linen pants has an eye-catching bulge. Oh my god! If this is Tommy's cock in its passive state, how big will he grow when he's in action?

Today, I'm wearing my long, light brown summer dress that has a continuous line of buttons down the front. The two topmost buttons are opened and seductively reveal the gap between my breasts. Additionally, I always open the four bottommost buttons to have free movement. Now, I open four more bottom buttons as unobtrusively as possible and push the fabric of my dress off my thigh. I look down. I can see the translucent, black string on my panties that barely covers my crotch. Hmm, it doesn't take much imagination to picture how I look under the thin fabric. I lean back slowly, open my thighs, and nudge him with my knee. I want to give him the opportunity to send his eyes on a journey.

\section{Episode 2}

Meanwhile, I continue my inconsequential conversation. From the corner of my eye, I see Tommy staring at my lap. Anxiously, he starts to wriggle about in his chair. His nervousness is so sweet! Over the next few minutes, I repeatedly catch him looking down at me. His face has a lovely flush and, talking to me, he avoids making eye contact. I push my pelvis a bit forward so that Tommy can see every detail. A lip has gotten free and the black fabric digs into my gap. Surely, he still thinks he is getting these glimpses by accident. The next time he looks at me, I ask him, "Would you like some more?" He looks at me, perplexed.

Smiling, I offer him the bottle of wine. "Yes, I'd love some," he nods at me conspiratorially, "but not too much. I'm getting dizzy very fast." "Good, then just a bit to start," I say and pour him a little wine. Then my hand moves down to my lap and I push my slip to the side and release my pussy. With my fingers, I slightly spread my lips. Man, I'm so wet! My middle finger slides deep into my cunt and I feel a pleasant shudder. Slowly, I start to move my finger in circles.

\section{Episode 3}

I'd love to pleasure myself on the table in front of everyone. To cool down, I pull my finger out of my gap and put the trembling hand on the table. Still glistening because of my juices, my finger catches Tommy's gaze. I grab the stem of my wine glass cautiously and let my thumb and forefinger slide up and down slowly, splaying out my middle finger provokingly. Taking a look at my lap and seeing my opened labia, Tommy flushes. Immediately, his cock erects and causes an enormous tent in his pants. I'm getting nearly crazed with horniness! I just have to get his cock! I have to touch it, have to feel it in me, no matter what I have to do!

I'm sliding a bit towards him with my chair. His body trembles and I can hear that he has to pull himself together to be able to go on talking in a calm intonation. Carefully sliding my hand in his pants pocket, I trace the waistband of his underwear through the lining. I carefully start to pull down his boxers. Suddenly, the band catches on his erection. Oh, what a pleasant surprise: Immediately, he grabs through the other pocket and helps me to pull his underwear down. Not even a second later, I grab his rod. Only the thin fabric remains between our skins. 


\section{Study 1: Neutral Story (Control condition)}

\section{Episode 1}

When treated decently, a cat always lives in friendship with a person. Normally, it doesn't show as much attachment as a dog. But being met with the same love and diligence, its attachment will not be less than a dog's. A dog, being left to its own devices, is an uncouth creature. I have seen it hundreds of times in Egypt, where nobody befriends the wild and free-roaming dogs. They become impudent, treacherous, distrustful, and shy. The cats in our home have always been treated very kindly and have very often proven their affection and attachment. To the dismay of the women of our house, they regularly bring their recently slain prey and the cats do not eat the prey until they have been praised for their skill and ability. When I was a boy, I knew two cats that were not only pleasant towards friends, but towards strangers. We children hugged them, and they accompanied us on our way home in the evenings. It took half an hour, but the way did not seem to be too long for them. They never left our sides before we reached our house. Schach, a friend of mine, once told me the following story: When I still lived in my father's house, I had a very close friendship to our old house cat, a magnificent animal. "Riese", as we children called her because of her considerable size, was quickly drawn to me.

\section{Episode 2}

The cat was my neighbor at the table as well as my bedmate and when she was annoyed, whipping forcefully with her tail, nobody was more able to calm her than I was.

I never went to the forest without being accompanied by the cat. In my absence, she seemed to be bored and when she was without my company for a long time, she went to the forest alone, probably hoping to meet me there. Usually, she waited for my arrival and went home with me. Being very curious, she was interested in everything. When I secretly turned off on a side trail, she was immediately on my scent and - after having smelled and licked me - quietly took her place next to me until I went on.

When I went to a private school two hours away from home in 1834, Riese accompanied me again and stayed here for the whole duration of my studies, for three and a half years. There, I made a very pleasing observation: Riese had become the mother of two lovely kittens. Then, misfortune befell her and she was caught and separated from her dependent kittens.

I could not possibly leave the kittens to die and came up with a plan to rescue them. In the neighborhood, another cat had lost her young. She was chosen as foster mother. Willingly, she assumed the care of her stepchildren, suckling, licking, and cleaning them as well as possible.

\section{Episode 3}

But one day, the rightful mother returned. Riese had escaped from captivity and immediately hurried home. I brought her to the caretaker of her kittens. Pleased, purring and screaming, she hurried to her kittens and laid down next to them in the basket to assume her maternal duties. From then on, the kittens were suckled, treasured, and reared by both of their mothers, first by one of them, then by the other. If faced with danger, the two mothers united to form a furious resistance. Being accompanied by his owner, a butcher's dog who came to the yard where the cats romped about with their kittens. The dog was attacked by the mother cats, nearly lost his eyesight, and ran straight away.

After my college days, I returned home with Riese. Later, I lost sight of the admirable animal, since we had to separate forever. Where I live now, I had the opportunity to know an equally companionable cat. I brought up a cat, which was not only a real beauty, but also an example of cleanliness and good behavior. The whole neighborhood loved the animal and gave him milk very often. Often, he accompanied me on my way to the forest and sat far away from home, waiting for hours on the edge of the path where I had to go. Coming home at midnight, I heard his voice in the middle of the forest - and with a single bound, he sat on my shoulder. Not a single time was it necessary to punish the cat. Moreover, it would have defeated the purpose, since the animal was sensitive to even a harsh word. 


\section{Study 2: Erotic stories (Sexual arousal condition)}

\section{Story 1}

The party ended early. My boyfriend sits alone listening to music. I wear a low cut dress that exposes the tops of my suntanned breasts. I feel his warm skin when I playfully nibble his ear. Sliding onto his lap I begin exploring his mouth with my tongue. As he guides his hand onto my breast I moan, "Oh babe, I need you so bad, fuck me." I reach back, unzip my dress and pull the front down. Excitedly I press his face into my huge tits. He licks and sucks my red nipples. As my passion mounts I push him back onto the couch and tore our clothes off. My mouth explores his body. My tongue laps the flesh of his excited cock. "Oh yes, that tastes so good," I groan. "I want it now." Placing his hard cock into my cunt I begin pumping. My breasts are bobbing as I hump him frantically. With a gasp I continue surging over his erection faster and faster with my moist cunt. I pump furiously until reaching a shattering orgasm.

\section{Story 2}

My boyfriend and I find a clearing to rest from our hike. My tight jeans and thin blouse display my inviting figure. As we rest in the cool grass, we begin necking. Our tongues begin excitedly exploring each other's mouths. Gently he begins caressing my firm round breasts, first over my clothes and then gradually his hands slipped under my blouse. With a sensuous moan I say, "Oh baby that feels so good, do it to me right now." He begins kissing my neck and breasts as he quickly removes my clothes. My nipples swell between his lips. Excitedly I beckon him to hurry. Naked, we fall together into the deep grass. I gently stroke his cock. As it hardened I bend down and begin sucking and kissing it while his mouth savours the fleshy succulence of my thighs and cunt. With a gasp of delight I roll over. "Oh yes, I need your cock now, quickly," I moaned. He eased into my warm pussy. We pumped wildly together before exploding into ecstatic orgasms.

\section{Story 3}

I am lying in bed in the morning with my boyfriend. Only the sheets cover the seductive curves of my sensuous body. I roll toward him and, slipping my warm hand under the sheet, begin to caress his stomach. I start to fondle his hardening prick and pubic hair. At the same time I slide my hot darting tongue into his mouth, I whisper, "I want you right now. I'm going to do it to you. I want you so bad." I begin to explore his body with my tongue as he hungrily sucks my engorged nipples and his fingers probe the slippery folds of my cunt. Rising up I straddle him and lowered myself over him, enveloping his cock with my warm wet cunt. "Oh yes I love it. I want you so bad," I moan. I rise and fall over him panting in ecstasy and straining my thighs apart engulfing him further inside me. My breasts bounce provocatively and my breath comes in short sharp gasps of pleasure as I furiously pump towards a fiery climax.

\section{Story 4}

I was lying on the deserted beach with my boyfriend. My bikini shows my firm breasts and inviting hips to their fullest. He leans over and begins to gently caress my warm flat stomach. He slips his hand under my suit and starts to fondle my damp silky pubic hair. At the same time sliding his tongue between my hot full lips he says, "I want you now, right here on the beach." "Oh yes, do it to me," I pant. We quickly shed our bathing suits. He begins to explore my body with his tongue, and then hungrily sucks my fully erect nipples while his fingers explore the slippery folds of my cunt. My body quivers in anticipation. As he plunges his cock into me, I arch my back, grinding my hips into him as I moan, "Oh yes, harder. I want you so bad." I wrap my velvet thighs tightly around his waist forcing him further into me. I shudder and moan with passion as we furiously screw to a fiery climax. 


\section{Study 2: Neutral stories (Control condition)}

\section{Story 1}

The Laundromat is humming with activity as people do their washing. A woman with long blonde hair is folding her clothes. Selecting the two washing machines beside hers, I begin sorting my clothes and distributing them between the two machines. Once they are loaded I add powdered soap. I notice that I do not have enough change. "Excuse me, do you have change for a dollar," I ask. The woman searches in her change purse and offers me four quarters. I thank her, take the change, and insert the quarters in the machine. I relax and wait as the washer begins filling with hot water. A while later, the machine gradually comes to a stop, having completed the wash and rinse cycles. I carefully remove the damp clothes and place them in an empty dryer. "That machine is not working," advises the woman. I thank her, and move my clothes to another machine. Selecting the hottest temperature to dry my clothes, I insert some dimes and push the start button.

\section{Story 2}

The restaurant is quiet and dimly lit; most of the tables are unoccupied. There are about a dozen other people there. I sit down and the waiter brings me a menu. "Would you like anything from the bar?" he asks. I order a beer and start to examine the menu. I have never eaten here before but the prices look reasonable. When the waiter returns with my beer I am ready to order. I have decided to have the steak with fried mushrooms and a salad. "Would you like French fries or a baked potato?" the waiter asks. I decide on a baked potato and I sit back to enjoy my beer and wait for my food. When it arrives I am pleasantly surprised by the size of the portions. My steak is enormous and everything looks great. I am not disappointed when I begin eating. Everything tastes incredible. I finish my meal and then sit for a while and leisurely enjoy some coffee.

\section{Story 3}

Bright and sunny, a perfect day to go to the zoo; because it is Wednesday there are very few other people there and I have a chance to examine the animals at my leisure. I have always been fascinated by the big cats so I head towards the tigers. I get there just as the zoo keeper is feeding them. It is incredible watching them tear into the huge chunks of raw meat. After they all have finished eating they all lay down in the shade and go to sleep. So I move on to something a little more interesting. The monkey house is bustling with activity. I watch hypnotized as several of the younger monkeys chase each other, swinging from ropes and tree branches on their compound. Several times I am sure that one of them would fall. But they always seem to catch themselves at the last moment and then continue with their hectic chase. I continue watching for about thirty minutes and then move on, heading towards the elephants.

\section{Story 4}

I am alone, just browsing through the large shopping plaza. Ahead I notice a group of children busily talking. As I approach, a young boy of about ten years of age smiles and asks if he could speak to me for a moment. He wears a t-shirt with writing on it. I agree to stop and talk to him for a while. He says, "Would you like to buy some tickets for our school raffle?" "You could win a microwave oven." He explains that the raffle was to buy new musical instruments for the school band as well as to help finance a school trip. This seems to me to be a worthwhile cause. So I ask him how much each ticket cost. The young boy explains that each ticket is two dollars but a book of five would only cost me nine dollars. I decide to go for the whole book of tickets. As I hand him the ten dollar bill, I ask if there are any other prizes besides the microwave oven. "Oh yes!" he replies, "you could also win a digital watch or one of several dinner theatre passes for two." I am excited whether I will win one of these prizes. 